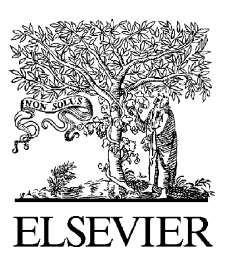

EDITORIAL

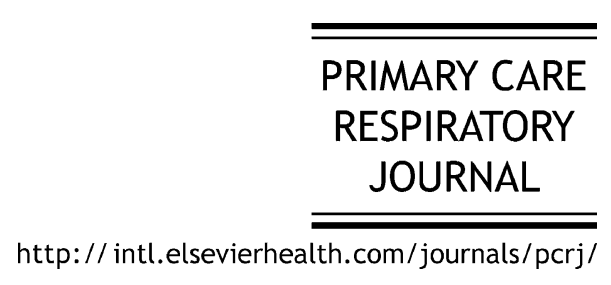

http:// intl.elsevierhealth.com/journals/pcrj/

\title{
What's in this issue
}

Having had a landmark year in 2005 with the advent of bi-monthly publication of the Primary Care Respiratory Journal (PCRJ), we now have another landmark in the Journal's evolution. The PCRJ was awarded full Medline/Index Medicus listing by the NLM/Medline Committee in February this year, with backdated Medline listing for PCRJ papers to January 2004 (volume 13, number 1). This is a great achievement for the Journal, its contributors, and its readers, and is the culmination of 10 years' hard work on its development. The PCRJ is funded by, and is the Journal of, the UK General Practice Airways Group (GPIAG). We therefore include in this issue an editorial written by the PCRJ editors, the PCRJ publications na d $\mathrm{g} \in \mathrm{r}$, the Chairman of the GPIAC C en Eral Committee and the GPIArghbief Executive [1], whish pats this importantdevelopment into onte), tand which thanks those who have played a role in the Journal's success.

Though our Editor-in-Chief Mark Levy would be the first to admit that these last 10 years have been very much a team effort, he has nevertheless been the key figure in the PCRJ's evolution and development. Mark's dedication, academic and editorial integrity, vision, and inspirational leadership have been outstanding, and it is an absolute privilege to work with him. On behalf of us all I pay tribute to Mark, and thank him immensely for his hard work and efforts over the last 10 years. Here's to the next 10 years, Mark....

It is heartening to see PCRJ papers generating correspondence and questioning the status quo of health service infrastructure and organisation. In December last year we published the UK Eastern Region Confidential Enquiry into asthma deaths [2], which confirmed that most patients who die from asthma have significant psychosocial and/or behavioural factors which put them at risk for near-fatal attacks and asthma death. The paper reiterated the recommendation $[3,4]$ that these 'at-risk' patients should be entered onto primary care at-risk registers - but did highlight the fact that there was little direct evidence for such registers. In a thoughtful accompanying editorial, Richard Ruffin from Adelaide [5] argued that health service systems had to change. Chris Griffiths et al published a randomised controlled trial (RCT) on specialist nurse intervention for high-risk patients in East London in 2004 - the El.FCTR tudy [6] - which incorporated angat-rick register as one of the inter trition:, and to which they referred irctheir qualitative paper in the PCRJ in June last year [7/ in cu. last issue we published a retris ective pilot study on the introduction and implementation of an at-risk register in one general practice in the UK [8]. In his letter in this issue [9], Brian Harrison comments on Mike Noble et al's paper [8] and calls for a properly-funded large prospective RCT on at-risk asthma registers in primary care. It seems highly unlikely, however, that at-risk registers per se will make a difference without proper implementation. What do you think? Write to us at info@gpiag.org.

In a similar vein, the GPIAG Research Unit at Aberdeen led by David Price and Thys van der Molen present in this issue a qualitative grounded theory study on 14 patients, most of whom had severe and/or difficult asthma, which focuses on the patients' experiences relating to their asthma and their consultations with healthcare professionals [10]. In a recent review [11], 'severe' asthma was defined as occurring in a patient who has been admitted to hospital with an acute severe asthma attack or who requires BTS/SIGN [3] Step 4 or 5 treatment, and 'difficult' asthma was defined as being present in a patient with a confirmed diagnosis of asthma whose symptoms and/or lung 
function abnormalities are poorly controlled with prescribed treatment which experience suggests would usually be effective. Mandy Moffat et al's data show that patients with severe and/or difficult asthma underplay symptoms, they do not discuss non-medical factors which may impact on asthma control in primary care consultations, and that this poor communication is associated with an underestimation of disease severity [10]. This begins to explain why various psychosocial and behavioural risk factors put patients at risk of nearfatal attacks and death $[2,4,8,12,13]$.

Another paper in this issue also challenges the status quo - but this time it is the undergraduate teaching of allergy in UK medical schools which is under the microscope. Aziz Sheikh and his colleagues report a systematic analysis of the learning objectives and teaching modules within the five-year undergraduate medical course at the University of Edinburgh [14], and show that there are significant gaps in the curriculum at present. There is widespread concern about the undergraduate and postgraduate teaching of allergy in medical schools [15] and the management of allergic problems in primary care [16]. As Shuaib Nasser wrote in his editorial in the August issue of the PCRJ last year [17], the UK National Health Service has been wrong-footed by the present unexpected allergy epidemis, and it: E vitally important that primary andi secolcary care services work togethe to bring about a sea-charise inth = way allercie diseuse is perceiven (n) pioved allergy teaching in medical schools would be a good start.

We include two reviews in this issue. The first, by Onno van Schayck and Jim Reid [18], outlines the clinical evidence supporting combination treatment with long-acting beta-2 agonists (LABAs) and inhaled corticosteroids (ICS) for patients with chronic obstructive pulmonary disease (COPD). They highlight the multicomponent nature of COPD, and present the evidence relating to improvements in lung function, symptoms, health status, exacerbations, and mortality, in COPD patients treated with LABA/ICS combination inhalers. The second review, from Adnan Custovic's group at the Wythenshawe Hospital in Manchester [19], presents the evidence for allergen avoidance in the secondary and tertiary prevention of allergic disease. Secondary preventive measures are designed to halt the progression of disease in individuals who are at high risk for developing clinical allergy but who have not yet developed specific symptoms, whereas the objective of tertiary prevention is to prevent exacerbations in patients with established allergic disease. They highlight the rationale for the use of environmental control, and review the evidence relating to mite allergen, pet allergen and food allergen avoidance.

We also include in this issue an editorial written by the COPD Exacerbations Task Force led by Bartolome Celli which sets out five Key Action Points which urgently need to be implemented by healthcare professionals and providers in order to achieve effective implementation of current evidence-based guidelines for the management of COPD [20]. And Mike Thomas and colleagues from Aberdeen present interesting prescribing data from 2003 showing that $27 \%$ of 22,027 patients who had a quantifiable ICS daily dose recommendation were on high-dose ICS therapy $(>800 \mathrm{mcg} /$ day), and of these, $32 \%$ were not prescribed add-on therapy [21].

The PCRJ is not only the Journal of the GPIAG, but is also the Official Journal of the International Primary Care Respiratory Group (IPCRG). As we have written in our editorial [1], we are enormously grateful to the IPCRG for its support of the Journal over the last few years. The IPCRG now has thousands of members in 34 countries worldwide, and meets for its Third World Conference in Oslo on June 8th this year. We are detighted thoublish the Conference Abstractsongtheirtsehalt in this issue of the PCRJ.

ClFin.ly, our News section reports the latest news ariferento from the world of primary care respilatory medicine. In particular, we are delighted to announce the recent appointment of Onno van Schayck as an Assistant Editor of the PCRJ.

\section{References}

[1] Levy ML, Stephenson P, Griffiths C, et al. Primary Care Respiratory Journal is awarded full Medline/Index Medicus listing. Prim Care Resp J 2006;15(3):136-8.

[2] Harrison B, Stephenson P, Mohan G, Nasser S. An ongoing Confidential Enquiry into asthma deaths in the Eastern Region of the UK, 2001-2003. Prim Care Resp J 2005;14(6):303-13.

[3] British Guideline on the Management of Asthma. BTS/SIGN. Thorax 2003;58(Suppl l).

[4] Mohan G, Harrison BDW, Badminton RM, Mildenhall S, Wareham NJ. A confidential enquiry into deaths caused by asthma in an English health region: implications for general practice. Br J Gen Pract 1996;46:529-32.

[5] Ruffin R. Asthma deaths - are we doing enough? Prim Care Resp J 2005;14(6):276-8.

[6] Griffiths C, Foster G, Barnes N, et al. A specialist nurse intervention to reduce unscheduled care for asthma in a deprived multiethnic area: the East London randomised controlled trial for high-risk asthma (ELECTRA). BMJ 2004;328:144-50.

[7] Foster G, Gantley M, Feder G, Griffiths C. How do clinical nurse specialists influence primary care management of asthma? A qualitative study. Prim Care Resp J 2005;14(3):154-60. 
[8] Noble MJ, Smith JR, Windley J. A controlled retrospective pilot study of an 'at-risk asthma register' in primary care. Prim Care Resp J 2006;15(2):116-24.

[9] Harrison BDW. Letter: 'At-risk asthma registers in primary care'. Prim Care Resp J 2006;15(3):179-80.

[10] Moffat M, Cleland J, van der Molen T, Price D. Suboptimal patient and physician communication in primary care consultations: its relation to severe and difficult asthma. Prim Care Resp J 2006;15(3):159-65.

[11] Harrison BDW. Difficult asthma in adults: recognition and approaches to management. Intern Med J 2005;35:543-7.

[12] Sturdy PM, Victor CR, Anderson HR, et al. Psychological, social and health behaviour risk factors for deaths certified as asthma: a national case control study. Thorax 2002;57:1034-9.

[13] Kolbe J, Fergusson W, Vamos M. Case-control study of severe life threatening asthma (SLTA) in adults: psychological factors. Thorax 2002;57:317-22.

[14] Shehata $Y$, Ross M, Sheikh A. Undergraduate allergy teaching in a UK medical school: mapping and assessment of an undergraduate curriculum. Prim Care Resp J 2006;15(3):173-8.

[15] Royal College of Physicians. Allergy: the unmet need. A blueprint for better patient care. London: Royal College of Physicians; 2003.

[16] Ryan D, Levy M, Morris A, Sheikh A, Walker S. Management of allergic problems in primary care: time for a rethink? Prim Care Resp J 2005;14(4):195-203.

[17] Nasser S. Improving the provision of allergy care. Prim Care Resp J 2005;14(4):183-5.
[18] van Schayck CP, Reid J. Effective management of COPD in primary care - the role of long-acting beta agonist/inhaled corticosteroid combination therapy. Prim Care Resp J 2006;15(3):143-51.

[19] Marinho S, Simpson A, Custovic A. Allergen avoidance in the secondary and tertiary prevention of allergic disease: does it work? Prim Care Resp J 2006;15(3):152-8.

[20] Celli B, Cross S, Grossman R, et al. Improving the care of COPD patients - suggested action points by the COPD exacerbations taskforce for reducing the burden of exacerbations of COPD. Prim Care Resp J 2006;15(3): $139-42$.

[21] Thomas M, Leather D, Price D. High-dose inhaled corticosteroids and add-on therapy use in adults with asthma in the UK in 2003: an observational study. Prim Care Resp J 2006;15(3):166-72.

Paul Stephenson* Deputy Editor, PCRJ

The Christmas Maltings and Clements Practice, Haverhill, Suffolk, UK

* c/o GPIAG, Smithy House, Waterbeck, Lockerbie, DG11 3EY, UK. Tel.: +44 (0)1461 600639; fax: +44 (0)1461 207819 . E-mail address: paul.stephenson@gp-d83012.nhs.uk

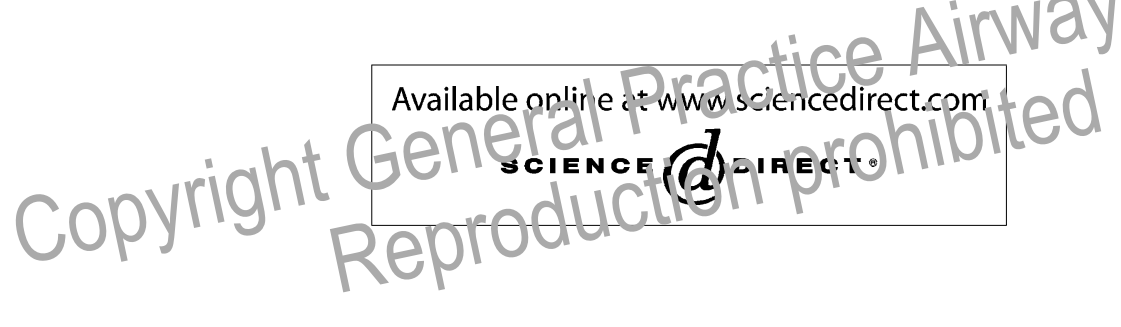

Available online at http://www.thepcrj.com 